\title{
Using the Internationally Recognized Frameworks of Nursing Competences to address the challenges of nurse refugees without documentation
}

\author{
Maria Cassar* \\ doi: http://dx.doi.org/10.18543/tjhe-8(1)-2020pp53-73
}

Received: 16 April 2020

Accepted: 31 August 2020

\begin{abstract}
Individuals seeking refuge in host countries is a global reality. Some of these individuals are qualified nurses. If, and when, the documents pertaining to a nurse qualification are not presented to the respective authorities of a host country, the challenges for these qualified nurses to secure registration and employment as nurses are numerous and often unsurmountable. Access to higher education opportunities is similarly compromised in the absence of relevant documents. This is happening against the backdrop of a widely reported global shortage of qualified nurses, and an extensive effort and investment to address this shortage in many countries. This paper explores the feasibility and appropriateness of applying internationally recognized frameworks of competences of nurses, to processes which seek to evaluate and verify the nurse training and qualification claimed by refugee nurses. The author seeks to determine whether such frameworks of nurse competences may effectively and efficiently contribute towards initiatives which are geared towards addressing the gap in (qualification) document availability, traceability, verification and reproduction of nurse refugees. A critical consideration of a few existent initiatives is presented in view of exploring, the identification of a tool which may enable a homogenous transnational approach which is consistent across salient parameters.
\end{abstract}

Keywords: Nurse refugees; competences frameworks; nurse qualification; nursing shortage; Tuning.

* Maria Cassar (maria.cassar@um.edu.mt), RN, PhD, is Head of the Department of Nursing, University of Malta (Malta).

More information about her is available at the end of this article.

Disclaimer: The exploratory exercise reported in this paper was supported through a scholarship awarded to the author by the International Tuning Academy. The views and opinions expressed in this paper are solely and entirely those of the author and do not necessarily correspond with those of the International Tuning Academy, Bilbao, Spain.

Acknowledgements are due to Dr Maria Yaroush, from the International Tuning Academy, for her guidance and support. 


\section{Background}

The world continues to witness individuals leaving their home country and seeking refuge in another country for whatever reason. The Eurostat figures available at the time of preparation of this paper demonstrate that the EU member states granted protection to more than 185,000 asylum seekers in 2014, up by almost $50 \%$ compared with 2013. In turn, during the third quarter of 2015, more than 410,00 first time asylum seekers had registered for international protection in EU members states. This figure was almost double that registered in the second quarter of 2015. The number of first-time asylum seekers in the third quarter of 2016 was almost 360,00 in member states of the EU bringing the total to almost 950,000 in Sept 2016. 612700 first-time asylum seekers applied for international protection in the Member States of the EU in 2019. Not all asylum seekers are granted refugee status in the host country where their application is processed. Nevertheless, these figures leave little scope for discussing whether refugees, to-date, are seeking to re-start their lives in different countries, and that they are doing so in large numbers.

The United Nations 1951 Refugee Convention²defines a refugee as:

A person who owing to a well-founded fear of being persecuted for reasons of race, religion, nationality, membership of a particular social group or political opinion is outside the country of his nationality and is unable or, owing to such fear, is unwilling to avail himself of the protection of that country; or who, not having a nationality and being outside the country of his former habitual residence as a result of such event is unable or, owing to such fear, is unwilling to return to it.

This paper draws upon such definition and the word refugee is used in the light of this definition. When refugees reach a host country, they often arrive with educational qualifications and work experience, but with no documents. This means that refugees are often unable to use their qualifications to work or to access higher education. This entails a loss for the individual refugees, and a waste of knowledge, skills and expertise to the host country. In addition, this also comprises a loss to the refugees' home

1 “Eurostat," European Commission, accessed August 26, 2020, http://ec.europa.eu/ eurostat/search?p_auth=80e9bK8q\&p_p_id=estatsearchportlet_WAR_estatsearchportlet\&p_p_ lifecycle $=1 \&$ p_p_state $=$ maximized\&p_p_mode $=$ view\&_estatsearchportlet_WAR_ estatsearchportlet_action=search\&text=asylum+seekers.

2 "UN Refugee Convention," UNHCR, accessed March 8, 2017, http://www.unhcr.org/ pages/49da0e466.html. 
countries. Refugees are greatly needed in their home countries. Retaining and extending their competencies while they are abroad will optimize their potential to help rebuild their home countries upon their possible eventual return. The need to develop processes to be able to assess the qualification of refugees is therefore clear on various fronts and for various reasons. The challenge lies with determining a valid assessment of one's claimed qualification. The validity needs to hold, not only where the refugee first arrived but also anywhere the refugee may subsequently seek residency at a later time. ${ }^{3}$

Some refugees are nurses in their home country. This paper focuses on qualified general nurses. "Qualified general nurse" here refers to the trained individual who, by mean of training and qualification, is entitled to hold the protected title of a general nurse. In turn, such title is protected in the sense that it is assumed only if and when a certain level and nature of training is successfully completed. The central bearing of the qualified nurses in the workforce of any health care system is globally acknowledged. Nurses and nursing care has been widely distinguished as the backbone a health care system ${ }^{4}$ Against the backdrop of a widely reported global shortage of qualified nurses, and the extensive effort and investment to address this shortage in many countries, the reality described above is even more concerning, perhaps ironic. This paper focuses on the context of Malta, a small independent island state in the European Union, situated in the Mediterranean seas between Sicily and North Africa. In Malta, too, a shortage of nurses is consistently reported and efforts to recruit nurses into the health system are continually prevalent. The world is experiencing a shortage of nurses, whilst, concurrently, qualified nurse refugees are unable to register and work as nurses, because of gaps in their documents when they reach a host country. This prevailing scenario suggests that in the context of nursing, the need to determine and recognize the qualifications of refugees who are nurses is not merely indicated, but it is urgent and pertinent to welfare of health care systems around the world. The application and use of the internationally recognised frameworks of competences of nurses towards addressing this need was explored by the author. This paper reports the exploration of the application of the TUNING framework.

3 "Imagine for a Second," Council of Europe, accessed April 1, 2017, https://www.coe. int/en/web/education/documentary-on-project-european-qualifications-passport-for-refugees.

${ }^{4}$ Peter I. Buerhaus, David I. Auerbach, Douglas O. Staiger, and Ulrike Muench, "Projections of the long-term growth of the registered nurse workforce: a regional analysis," Nursing Economics 31, no. 1 (2013): 13. 
Tuning projects have to-date functioned as instruments for promoting understanding and cooperation between institutions, countries and regions around the globe. These projects bring together different stakeholders to agree on competences necessary to enter a professional community or a community of practice in terms of employment. In Tuning projects, experienced and knowledgeable recognised experts in specific subjects, collectively, develop competence frameworks in a subject area, by focusing on competence-based criteria, which a student is expected to develop through a training programme.

The main strengths of Tuning projects are (a) openness to the different cultural contexts in which academics and students in different countries and regions work, and (b) the active quest for a mutually understood discourse. ${ }^{5}$ Such characteristics of Tuning- its transnational and inter-regional nature posit the outputs of these projects, that is frameworks of competences, as a possible tool for mapping the qualifications of nurses with missing or unverifiable documents who seek refuge in a host country.

\section{Initiatives directed at addressing refugees with inadequate qualification documentation}

A few initiatives have been developed over the last few years through which refugees' qualifications may be assessed when they cannot be adequately documented. This section presents the initiatives which are most widely reported in the literature, documentation and resources related to refugees in Europe which were available, in English language. The author did not scan for initiatives across the entire fifty-five signatories of the Lisbon treaty (referred to below).

The first initiative which is outlined in this section stems from an exercise in Greece, which is expanding across nations and is gathering the contribution and participation of various other European countries and partners, including the Council of Europe (CoE), and the United Nations High Commissioner for Refugees (UNHCR). National initiatives in Norway and Germany are also presented. The fourth and last initiative presents an initiative which comprises a transnational online resource.

5 “Tuning Projects,” Tuning Academy, accessed February 22, 2017, http://tuningacademy. org/. 


\section{II.1. The European Qualifications Passport for Refugees (EQPR) in Greece}

The issuing of a European Qualifications Passport for Refugees (EQPR) entails a process whereby an evaluation of documentation that a refugee provides is carried out, coupled with a self-evaluation of the refugee and a structured interview with two qualified credential evaluators. The EQPR can be used for access to higher education or employment. Several refugees assessed during the pilot project which tested this process in Greece have already been able to use the EQPR to access higher education studies. ${ }^{6}$

The EQPR has been explicitly mentioned in the recommendation made by the Lisbon Recognition Convention Committee on the recognition of qualifications held by refugees, displaced persons and persons in a refugee situation, in November 2017.7 The European Qualifications Passport for Refugees draws largely on the concept of the Nansen Passport for Refugees of the 1930s. In line with the scope of the Nansen passport, the EQPR aims to establish a multinational, quality assured framework in Europe for the recognition of refugees' competence. It therefore provides a document that can be utilized across European countries.

\section{II.2. Recognition Procedure for Persons without Verifiable Documentation (UVD-procedure) in Norway}

Norwegian Agency for Quality Assurance in Education (NOKUT) developed the Recognition Procedure for Persons without Verifiable Documentation (UVD-procedure) to meet the needs of applicants with foreign higher education qualifications who cannot be granted general recognition in Norway due to missing, insufficient or unverifiable documentation. This procedure is directed specifically at refugees and persons in a refugee-like situation without verifiable documentation. The procedure comprises the completion of a survey form by an applicant refugee. The survey form is returned to NOKUT with any documentation on language skills, residence permit, a Curriculum Vitae (CV) and work testimonials. These are evaluated in view of determining whether the applicant fulfils the formal requirements to proceed with the recognition

\footnotetext{
6 “EQPR: From vision to reality,” EAIE, accessed March 30, 2017, https://www .eaie.org/ blog/european-qualifications-passport-refugees.html.

7 "New recommendation on recognition of qualification held by refugees," $\mathrm{COE}$, accessed February 27, 2018, https://www.coe.int/en/web/education/-/new-recommendationon-recognition-of-qualifications-held-by-refugees.
} 
procedure. If deemed eligible to proceed with the recognition process, the applicant is invited to a preliminary interview and subsequently to an interview with a panel of credential evaluators and experts designated by NOKUT. NOKUT will decide based on the report from the panel of experts regarding the general recognition of claimed qualifications of the applicant refugee. So far, this procedure of recognition is perceived as readily implementable and highly efficient. NOKUT will therefore continue issuing NOKUT's Qualifications Passport for Refugees. ${ }^{8}$

\section{II.3. Initiatives in Germany}

The Federal Recognition Act simplifies and standardises procedures for the evaluation of foreign professional or vocational qualifications governed by Federal Law. Article 14 of the Federal Recognition Act opened such procedures to target groups not previously accommodated. Specifically, this article notes that if the applicant cannot submit all or part of the documents required for the establishment or assessment of qualification equivalence, for reasons beyond his or her control or if submission of relevant documents involves an unreasonable expenditure of time and effort, the competent body shall apply other suitable procedures to establish the applicant's professional skills, knowledge and abilities required for comparison with corresponding German professional training. The Federal Recognition Act requests that an applicant explains the reasons for not submitting relevant documents. ${ }^{9}$ Also, it explains that suitable procedures to ascertain professional skills, knowledge and abilities may be used, such as work samples, interviews, practical and theoretical demonstration in real or simulated environments and discussion with experts. This means that if applicants are unable to produce written evidence in the process of having their foreign professional qualifications recognised, they can have their competences assessed, as part of a recognition procedure. This option is also enshrined in the Professional Qualifications Assessment Act which identified the qualification analysis approach. This analysis is a demonstration and assessment of competency and is not a test. It is therefore based on other procedural standards than an external examination. For example, the Prototyping Transfer project is an initiative of

\footnotetext{
8 “Nokut's qualification passport for refugees," NOKUT, accessed April 4, 2018, https:// www.nokut.no/en/nyheter-2016/NOKUTs-Qualifications-Passport-for-Refugees/.

${ }^{9}$ Dorothea Fohrbeck, "Recognition of foreign professional qualifications - the Federal Government's new Recognition Act," Berufsbildung in Wissenschaft und Praxis - BWP (Vocational Training in Research and Practice) Special Edition (2013): 9-13
} 
the Federal Ministry of Education and Research and is coordinated by the Federal Institute for Vocational Education and Training (BIBB). The project is geared towards the recognition of professional and vocational qualifications via skills analysis. ${ }^{10}$

\section{II.4. European Network of Information Centres in the European Region (ENIC) - National Academic Recognition Information Centres in the European Union (NARIC) website}

The site is a joint system initiative of the European Commission, the Council of Europe and United Nations Educational, Scientific and Cultural Organisation (UNESCO). This system seeks to verify the vocational or academic level of a qualification awarded in a foreign country, where this is known to the system. Amongst several resources pertaining to the evaluation and assessment of qualifications, the site comprises an area titled "Recognise qualification held by refugees - Guide for credential evaluators"11 This area stipulates that a process which is standardized, accessible, fair and transparent is to be established in dealing with refugees with missing documents. The third step of the recommended five-step process refers to the organisation of an examination/ test to allow for the demonstration of the knowledge, competences and skills of an applicant. The website falls short of providing specific examples of what such test or examination should comprise. However, it clearly suggests the use of a test or examination which accommodates a valid assessment of an applicant in relation to a profession or training in which one claims to have received training.

\section{II.5. Common factors across these initiatives}

Upon review of the sample of initiatives which are presented above, five common factors were elicited across the four different initiatives. Namely, all four initiatives (a) stem from the intent to satisfy the requirement of Article VII of Section VII titled "RECOGNITION OF QUALIFICATIONS HELD BY REFUGEES, DISPLACED PERSONS AND PERSONS IN A REFUGEE

10 "Recognition of foreign professional qualifications," BIBB, accessed February 16, 2017, https://www.google.de/search?s=true\&q=site:www.bibb.de Qualification recognition.

11 "Recognise qualifications held by refugees - guide for credential evaluators," ENICNARIC, accessed March 23, 2018, http://www .enic-naric.net/recognise-qualifications-heldby-refugees.aspx. 
- LIKE SITUATION" of the Lisbon Treaty, No 165, Convention on the Recognition of Qualifications concerning Higher Education in the European Region ${ }^{\circ}$ 1997. In this article, all fifty-five signatories are requested to:

Take all feasible and reasonable steps within the framework of its education system and in conformity with its constitutional, legal, and regulatory provisions to develop procedures designed to assess fairly and expeditiously whether refugees, displaced persons and persons in a refugee-like situation fulfil the relevant requirements for access to higher education, to further higher education programmes or to employment activities, even in cases in which the qualifications obtained in one of the Parties cannot be proven through documentary evidence. ${ }^{12}$ Also, all four initiatives comprise (b) an assessment component, and (c) the involvement of credential evaluators.(d) A main limitation of all the initiatives is that the assessment of the competences of applicants related to a profession is not guided by a tool in a consistent, structured, homogenous manner across different applicants and different sets of evaluators. (e) In addition, as noted with each initiative above, subject-specific tools or instruments for assessments are, in the norm, not available in all four initiatives; none were located for the subject of nursing and the profession of nurses.

\section{Regulation of Nurse Education}

Across the European Union (EU), nurse education is governed by Professional Qualifications Directive 2005/36/EC, amended in 2013. This directive stipulates that pre-registration nurse education programmes are to comprise (i) training across specific identified areas of care delivery and (ii) a specific number of hours of training of a theoretical and of a practical nature. The directive lists the set of knowledge and skills required by a general nurse but it does not comprehensively determine the competences which an exiting student nurse needs to hold upon completion of a nurse education programme. Therefore, although the directive for nurse education allows for the mobility and recognition of general nurses across countries wherein pre-registration programmes of nurse education include, as a minimum, the achievement of the competences of the directive, the referred directive is not an adequately apt vehicle for the assessment of nurse refugees who do not hold verifiable qualifications.

12 "Convention on the Recognition of Qualifications concerning Higher Education in the European Region," COE, accessed on April 3, 2018, https://www .coe.int/en/web/conventions/ full-list/-/conventions/treaty/165. 
Since the regulatory function of the Professional Qualifications Directive is not well posited for addressing the opportunity to recognize and accredit nurse refugees as registered nurses in a host country, a process of assessment of the training and qualification of a nurse refugee which (a) fits the respective regulatory structures of a context where a nurse refugee is to practice, and which (b) allows for transnational professional mobility of a nurse refugee, in indicated.

The gathering of the case studies presented below was carried out in an effort to inform the analysis and further development of policy and processes in this regard.

\section{Case studies from Malta}

This section presents snapshots of case studies from Malta. The case studies were not collected through a research study. A small number of refugees were simply invited to tell their stories, voluntarily, and permission to document their stories in this paper was sought. The scope of the exercise was to gather information and views regarding the experience of refugees in seeking registration as a nurse in Malta to inform the development of initiatives which may effectively and efficiently address their needs.

As noted earlier, geographically, the island of Malta lies between North Africa and Italy. It therefore serves as an apt conduit between two continents. Its often calm and safe surrounding seas offer a viable plethora of transportation for both regular and irregular travellers, as does its widely connected air-transportation system. Four nurse refugees and a medical doctor also a refugee, were asked by the author to share their experience of seeking professional registration in Malta, after they were granted refugee status in the country. These five refugees who shared their stories had good command of the English language. Permission was sought against a comprehensive explanation that whilst confidentiality of the interviews was secured, anonymity could not be entirely guaranteed in view of the very small context of Malta. All names used in the section below are fictitious. All were created by the author and bare no reference or association to the real names of the interviewees. In addition, the reported gender of the interviewees does not necessarily correspond to the actual gender of the refugee whose "story" is presented below.

Jordie, 48-year old female from Eritrea, applied for asylum in Malta in 2015. She completed nursing training in Eritrea and following this she worked as a nurse for twenty-two years, mostly in operating theatres in 
public hospitals in the country. As a qualified nurse, Jordie pursued short training programmes for qualified nurses offered by various NGOs and reputable entities, including USAID, Save The Children, UK, and by the European Commission - Humanitarian Aid \& Civil Protection (ECHO) and the Coordinamento delle organizzazioni per il servizio volontario (COSV). She was later forced to leave her home country with her family and hoped to work as nurse as soon as possible in another country. Registration as a nurse in Malta requires adequate proficiency in Maltese or English languages. Jordie's language skills met these language proficiency requirements. The documents needed to apply for recognition of her nurse training are however not all in hand. The competent authority needs additional information about the content of her nurse training. Jordie is unable to provide such information because it is not possible to contact the training entity in Eritrea because it has been burnt down during internal conflict in the country. All the buildings which housed the nursing school were destroyed through a fire, and all the staff in the building at the time perished. To-date, Jordie works as a carer in a residential home for the elderly, despite being a qualified nurse. The currency of Jordie's nurse training would need to be verified if and when the missing information about her training is ever located.

Heidi, a 26-year old female from Somalia, applied for asylum in Malta in 2017. She completed nurse training at bachelor's degree level at a university in Somalia in 2013. Heidi fled after a short working period as a qualified nurse in her homeland. Novel and passionate about her career, the only document she firmly held onto during the arduous travels to Malta was the bachelor's Degree qualification certificate. It is the only possession she held upon arrival to the host country. Her application to register as a qualified nurse in Malta has not been met because the competent authority is unable to verify the quality of her training with the respective university in Somalia, or with competent authorities in Somalia, for various political and operational reasons. Heidi works on product-manufacturing line in a private pharmaceutical company, despite being a qualified nurse.

Kimmy, is now 58 years old. She is Albanian and received her nurse training in Albania. Her journey as a refugee dates to the 1990s when she fled the then-troubled Albania in search of a better life and a career as a nurse in Malta. Her journey sheds light on the history of the struggles that refugees face when seeking registration in a host country. Kimmy had to re-enter "special" training in Malta for a year to be able to register as a nurse in the host country because the verification of the nurse qualification which she had at hand at the time did not satisfy the requirement of the respective competent authority. Establishing efficient contact with Albania to verify the document was not possible at the time. 
Klara's circumstance, now 50, also shed retrospective information about the challenges that nurse refugees encounter. French speaking Klara fled Sierra Leone in the mid -1990s and sought refuge in Malta in the hope of re-starting her life as a qualified nurse. Klara had no documents at all to note her nurse training. The only avenue towards registering and re-starting life as a nurse was to re-start nurse training from scratch. She chose to pursue that option, only to be relocated to another European country shortly after the completion of the nurse training programme in Malta. Klara was once again unable to work as a nurse, because of language skills insufficiency in the new host country. She could not speak, understand nor write the language of her new host country. Adequate proficiency in the language of a country is a requisite for employment across most professions in the health and social sector in many countries. Unable to learn yet another language after having mastered the English language during her years in Malta, Klara worked as carer for a few years until she gained right for residency, and therefore for mobility, in Europe. She relocated back to Malta and finally could register and recommence her nursing career, after a forced pause of a decade. The currency of Klara's nurse training in the context of the Malta is, at this point, debatable, and the need and opportunity for retraining and upskilling a point of contention.

These case studies illustrate the challenges associated with time lags between one's practice as a general nurse /doctor in a home country, and one's application for entry to the register in a host country. In countries where renewal of licence / professional registration obliges evidence of completion of professional development initiatives, such time lags may pose significant challenges. Such circumstances elicit a need for "orientation" or "return to practice" initiatives on the basis of both legal requirements of the professional and the employer, and patient safety. There are also economic implications since funds are needed to support the consequences of this time lag.

These nurses experienced what many nurse refugees are believed to go through. In line with the principles of case study exploratory work ${ }^{13}$ the author interviewed a refugee in Malta who is medical doctor, who in contrast with the above "stories" sought and acquired registration as a medical doctor in Malta despite gaps in the training documents at hand. Kyrill explained that upon application for registration as a medical, he was provided with the opportunity to practise as a medical doctor under the continual supervision of qualified staff. He did so for a few months. During these months the supervisor/s sought to verify the knowledge and competences of the surgeon against an international framework of standards. Kyrill was registered as a

${ }^{13}$ Peter Swanborn, Case study research: What, why and how? (London: Sage, 2010). 
surgeon on the register in Malta and has been practising as a surgeon, independently since.

\section{The use of Tuning frameworks of nurse competences}

This section presents a critical discussion of why and how the use of Tuning frameworks of nurse competencies may be applied towards addressing challenges associated with the registration of nurses without verifiable documents. The Tuning framework of nurse competences which was developed through the Tuning - Middle East and North Africa (T-MEDA) Project ${ }^{14}$ is mirrored in the output of other Tuning projects. The participants in the T-MEDA project spanned the widest of world regions in that the project involved participants from several countries across the Middle East and North African regions, besides those from Europe. Its output runs parallel to the frameworks developed through Tuning-Europe ${ }^{15}$ and TuningSouth America. ${ }^{16}$

With all projects, the resulting frameworks identified five overarching domains of competence. These are:

1. Professional values and the role of the nurse

2. Nursing practice and clinical decision making

3. Knowledge and cognition

4. Communication and interpersonal skills (including technology for communication)

5. Leadership, management and team working

${ }^{14}$ Abeer Saad Eswi, ed., Reference Points for the Design and Delivery of Degree Programmes in Nursing (Bilbao: University of Deusto, 2016).

15 Julia Gonzalez and Robert Wagenaar, eds., Tuning Educational Structures in Europe. (Bilbao: University of Deusto, 2003).

${ }^{16}$ Luz Gonzalez, ed., Higher education in Latin America: reflections and perspectives on Nursing (Bilbao: University of Deusto, 2014). 
Table 2

Framework of competences for qualified nurses

Adapted from Saad Eswi, Abeer, ed., Reference Points for the Design and Delivery of Degree Programmes in Nursing (Bilbao: University of Deusto, 2016)

\begin{tabular}{|c|c|}
\hline $\begin{array}{l}\text { Competencies associated with the } \\
\text { professional and attitudinal values }\end{array}$ & $\begin{array}{l}\text { Competencies associated with the } \\
\text { skills and role of the nurse }\end{array}$ \\
\hline $\begin{array}{l}\text { Provide holistic care. } \\
\text { Deliver Individual centred care. } \\
\text { Maintain Patient safety. } \\
\text { Practice within the respective code of } \\
\text { ethics and legal codes. } \\
\text { Culturally sensitive and respect for } \\
\text { dignity. } \\
\text { Promote life and quality of life at all } \\
\text { stages. }\end{array}$ & $\begin{array}{l}\text { Work under pressure. } \\
\text { Use the Nursing process effectively. } \\
\text { Meet individual, family and } \\
\text { community needs. } \\
\text { Work in an interdisciplinary team. } \\
\text { Act as an educator. } \\
\text { Act as an advocate of the individual, } \\
\text { family, community as well as } \\
\text { profession. } \\
\text { Provide quality patient, family and } \\
\text { community care. } \\
\text { Provide life support measures across } \\
\text { life span. } \\
\text { Apply coping strategies. } \\
\text { Ability to decide when to refer to } \\
\text { other professionals. } \\
\text { Perform basic nursing procedures. } \\
\text { Apply universal precautions of } \\
\text { Infection control measures. }\end{array}$ \\
\hline $\begin{array}{l}\text { Competencies associated with } \\
\text { communication }\end{array}$ & $\begin{array}{l}\text { Knowledge and cognitive } \\
\text { competencies }\end{array}$ \\
\hline $\begin{array}{l}\text { Maintain therapeutic nurse patient } \\
\text { relationship. } \\
\text { Communicate effectively with } \\
\text { individuals, families and communities. } \\
\text { Provide counselling. } \\
\text { Document and report accurately and } \\
\text { effectively. } \\
\text { Mentor other nurses and student } \\
\text { nurses. } \\
\text { Manage challenging behaviour of } \\
\text { patient with special needs. } \\
\text { Utilize new technology in } \\
\text { communication. }\end{array}$ & $\begin{array}{l}\text { Apply knowledge and theories into } \\
\text { practice. } \\
\text { Apply critical thinking and clinical } \\
\text { judgment. } \\
\text { Utilize research findings and evidence } \\
\text { based in practice. } \\
\text { Utilize health informatics. }\end{array}$ \\
\hline
\end{tabular}




\begin{tabular}{|l|l|}
\hline $\begin{array}{l}\text { Leadership and management } \\
\text { competencies }\end{array}$ & \\
\hline Ability to work in a team either as a & \\
member or a leader. & \\
Ability to make and take decisions. & \\
Ability to delegate work. & \\
Accept constructive feedback and & \\
criticism. & \\
Ability to plan for future actions. & \\
Develop self and others. & \\
Risk, crisis and disaster management. & \\
Ability to appraise others objectively. & \\
Adhere to organizational policies and & \\
regulations & \\
\hline
\end{tabular}

Table 2 presents the list of competences determined through the TMEDA project. The evidence which is available to-date suggests that the different competences identified in the Tuning projects are all relevant irrespective of practice context, role of the nurse or geographical location. ${ }^{14}$

\section{Table 1}

\section{Questions asked to the key informants}

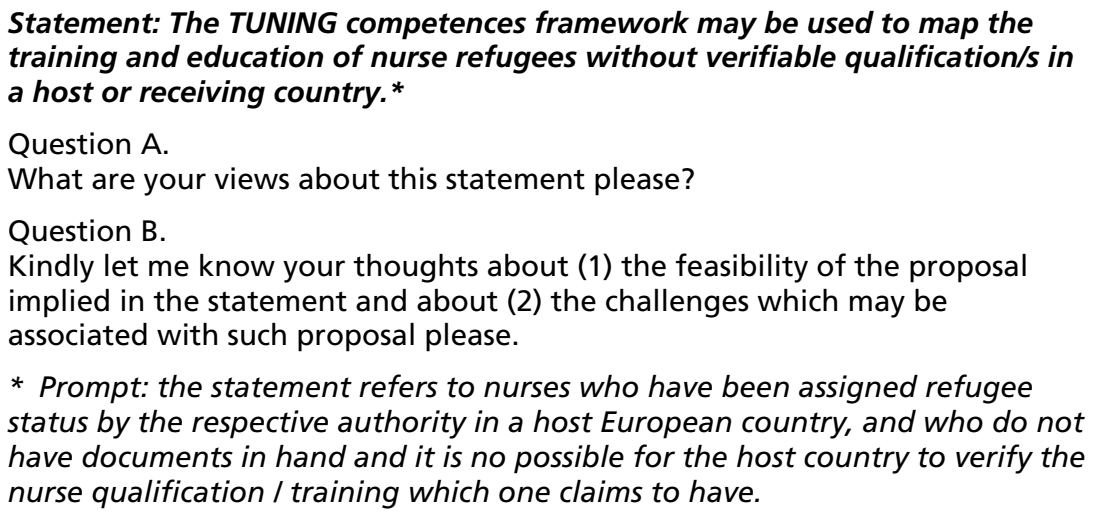

The author advocates the use of these parallel frameworks as a tool to guide the assessment and evaluation component of processes which seek to determine the qualification of nurse refugees. To inform the discussion 
around this contention, using the Key Informant Technique ${ }^{17}$ the author sought the views of a set of (1) key individuals from the Tuning projects, $(\mathrm{n}=5)$ and (2) key individuals who operate within existent processes which address the reality of undocumented refugees $(n=2)$. The key informants were invited to answer the two questions noted in Table 1. These Key Informants were identified by the author as being the key players in the field of focus, that is nurse registration regulation.

The key informants were all convinced that a recognition problem does exist and that it needs to be solved. The information gathered from the key informants was organised into six aspects or observations pertaining to the feasibility and appropriateness of the use of the Tuning frameworks of nurse competencies, as a tool to guide the assessment and evaluation component of processes which seek to determine the qualification of nurse refugees, if and when documents are missing, incomplete, unverifiable or untraceable. There were; (1) the rights of nurse refugees for professional recognition, (2) the importance of safeguarding patients and recipients of nursing care, (3) the need to be fair with documented professionals, (4) the emphasis on discouraging irregular migration, and (5) political will and the availability of and access to adequate resources needed to deliver political will.

\section{V.1. "They have rights which need to be addressed!» $v s$ «Patients need to be safeguarded from an inadequately competent workforce!»}

The two phrases noted in the title of this section were lifted from the responses of the key informants. They capture a main message which echoed in the shared views of the key informants. The key informants all emphatically highlighted the tall challenge of balancing (a) the rights of nurse refugees to be recognised as nurses, despite missing documentations, against (b) the right of a recipient of care or service user to optimal safe care delivery by a qualified nurse. A discussion about these rights is beyond the scope of this paper. On the other hand, a discussion regarding the use of the Tuning frameworks of nurse competences as a tool to address and balance these two rights is hugely relevant.

The Tuning frameworks may offer an apt tool towards adequately ensuring that nurse refugees with missing or unverifiable documents have the competences expected by experts and professionals in many countries. The

${ }^{17}$ Martin N. Marshall, “The key informant technique,” Family practice, no. 13 (1996): 92-97. 
Tuning frameworks may enable a consistent, structured, fair, transparent, objective avenue towards assessing and determining an applicant's competence as a nurse. Likewise, recipients of care or services users, often ill patients, are spared from the risks and dangers associated with inadequately competent nurses. Moreover, nurse refugees are spared from the prevalent reality of being denied the opportunity to work as a nurse or of having to rely on special, ad hoc or «tailor made » consideration and treatment by respective authorities rather than structured pan European processes, comprising standardised tools.

\section{V.2. «The system needs to be fair with documented professionals! »vs «It would encourage irregular migration! »}

The phrases in this title once again capture the salient concerns of the key informants. A struggle between (a) the commitment to help and accommodate the needs of individuals who would have entered a country through channels of irregular migration and granted refugee status in a country, and (b) the commitment to fully respect and safeguard the rights of regular (and fully documented) individuals was revealed. The key informants commented that processes which address the rights of nurse refugees, should not jeopardise nor compromise the rights of documented professionals. Also, such processes should not, nor be seen to encourage channels of irregular migration.

These concerns once again point towards the need for a robust, objective, formal, structured approach or tool of assessment of competence of an applicant nurse refugee, which may be used across different countries and contexts in a consistent, transparent and fair manner. In turn, these concerns point toward the existent Tuning frameworks of nurse competences as an apt tool in this regard. Tuning is a political neutral process embracing different nations, cultures and political contexts. Its outputs may therefore be accommodated and utilised within varying scenarios, situations and populations.

\section{V.3. «There is not enough political will! » $v s$ «Despite the political will, the resources for action are inadequate! »}

The debate over (i) the actual, and (ii) the perceived or projected political willingness in a country, to address the needs of refugees without documents is multifaceted. The key informants referred to this debate. The main line of observations which were shared with the author illustrated that often there is 
a gap between the actual willingness and the perceived or projected political willingness to address the needs of refugees. Moreover, there is often a gap between the actual political willingness and the resources available to translate willingness to action.

These observations shed further scope on the use of Tuning frameworks for nurse competences towards addressing the needs of nurse refugees. The Tuning frameworks of competences of nurses are already existent and are ready for use. They have been developed in a consultative and participative manner across a consensus spanning many countries and different regions in the world. Therefore, the use of the Tuning frameworks of nurse competence (a) would potentially introduce a transnational standard tool for assessing nurse refugees with missing or unverifiable documents, at no additional (resource) cost, and (b) may entice and encourage laggard countries to adopt such a standard tool to maintain par performance with other countries. Maintaining par is, in turn, conducive with mobility of nurses across countries and mobility of nurses is very important if the demand for nurses is to be addressed in an efficient and effective manner in any country or health system..$^{18,19,20}$

\section{Conclusions and recommendations}

The world continues to witness increasing numbers of individuals seeking refuge in host countries. Many refugees hold professional qualifications, including nurse qualifications. Nurse regulation carries a history of episodes of change and adjustment during its evolution in Europe. ${ }^{21}$ The outcomes of the exercise reported in this paper suggest the need for host countries to develop regulatory structures which are valid and transferable, but which also accommodate and facilitate the mobility of nurse refugees with missing or unverifiable documentation. The exercise also revealed that

18 Andrea Baumann et al., Internationally Educated Nurses in Ontario, 2nd ed. (Nursing Health Services Research Unit, Government of Ontario), accessed on March 22, 2018,

https://fhs.mcmaster.ca/nhsru/documents/

SeriesReport3InternationallyEducatedNursesinOntarioMaximizingtheBrainGain.pdf.

19 John Berry, "Integration and multiculturalism: Ways towards social solidarity," Papers on Social Representations, no. 20 (2011): 1-20.

${ }^{20}$ Jennifer Blythe et al.," Nurse migration to Canada: pathways and pitfalls of workforce integration," Journal of Transcultural Nursing, no. 20 (2009): 202-210.

${ }^{21}$ Alessandro Stievano et al., "Shaping nursing profession regulation through history-a systematic review, "International Nursing Review, 66, no. 1 (2018): 17-29. 
existent processes which address the challenges associated with missing, unverifiable or untraceable qualification rely heavily on panels of credential evaluators and experts. This large reliance on the contribution of evaluators and experts does not necessarily jeopardise or compromise the validity of the initiatives which are already in place across different countries. Nonetheless, against the backdrop of (a) a favourable legacy of harmonised nurse education structures for nurse education across Europe, as a result of the European directive for nurse education, and also (b) internationally recognised frameworks of competences, as are those of TUNING project and the International Council of Nurses (ICN), the observed lack of consistent use of standard tool or tools to evaluate nurse refugees' qualification and training in different countries is odd and possibly unfavourable. Since existent initiatives are not necessarily par, assessments and recognition are not automatically and immediately transferable across countries. The feasibility and appropriateness of using internationally recognised frameworks of competences to (1) harmonise the assessment component of the various existent processes and (2) to develop processes in other countries in a harmonised manner is believed to be significant. This contention draws upon the fact that, internationally recognised frameworks, as is the Tuning frameworks of competences, are the results and outputs of rigorous structured processes of wide participation, embracing extensive informed discussion and comprehensive consultation across relevant experts and stakeholders in many different countries across various world regions. Therefore, these frameworks may carry advantageous relevance to varying contexts and populations. Variations and adaptations to the frameworks of competences are indicated according to context since varying levels of pre-registration nurse training still prevail. For example, nurses' levels which are lower than a degree level (which is the training level that Tuning projects focus on) would necessitate a framework wherein the emphasis on management, leadership and clinical judgement competences are adjusted accordingly.

Nurse regulators across Europe, and overarching regulatory bodies and policy makers are invited to consider the adoption of this approach. Further pan-European and country-specific research is indicated. Such research will shed light on country-specific experiences, needs, readiness and resources in relation to adopting internationally recognised framework in this regard. The exploration, consideration and use of various international frameworks, as is the ICN's ${ }^{22}$ framework of nurse competences and the Nursing and Midwifery

${ }^{22}$ International Council of Nurses, An implementation model for the ICN framework of competencies for the generalist nurse (Geneva: ICN - International Council of Nurses, 2003). 
Council EU Aptitude test for nurses ${ }^{23}$ available in the UK is recommended. The different levels of qualified general nurses and nurse qualifications across the globe strongly suggest the need for the consideration of the use of different frameworks and tools. Extensive study of the ethical and legal implications of enabling the eligibility of nurse refugees without documentation to register as a nurse in a host country is indicated. This is indicated in view of honouring the obligations of a regulatory body to safeguard the interests of the population besides its obligations to honour the rights of individual nurse refugees. Other useful strategies to support the refugee, besides enabling professional registration through qualification and training verification need to be explored. These include language classes, upskilling and adjustment to societal norms and organisational cultures in simulated environments and supervised practice in clinical areas. The opportunity for temporary or probation registration in the course of pursing and receiving the above support may also be explored. Furthermore, the mechanisms for assessment, evaluation and monitoring of other requirements as are evidence of good character, clear conduct and favourable health status are to be explored and secured accordingly.

\section{Bibliography}

Baumann, Andrea., J. Blythe, K. McIntosh, and A. Rheaume. Internationally Educated Nurses in Ontario. 2nd ed. Nursing Health Services Research Unit. Government of Ontario. Accessed March 22, 2018.

https://fhs.mcmaster.ca/nhsru/documents/SeriesReport3InternationallyEducated NursesinOntarioMaximizingtheBrainGain.pdf.

Berry, John W. "Integration and Multiculturalism: Ways towards Social Solidarity." Papers on Social Representations 20, no. 1 (2011): 2-1.

BIBB (Federal Institute for Vocational Education and Training). "Recognition of foreign professional qualifications." Accessed February 16, 2017. https://www. google.de/search?s=true\&q=site:www.bibb.de Qualification recognition.

Blythe, Jennifer, Andrea Baumann, Ann Rhéaume, and Karen McIntosh. "Nurse migration to Canada: Pathways and pitfalls of workforce integration." Journal of Transcultural Nursing 20, no. 2 (2009): 202-210.

Buerhaus, Peter I., David I. Auerbach, Douglas O. Staiger, and Ulrike Muench. "Projections of the long-term growth of the registered nurse workforce: A regional analysis." Nursing Economics 31, no. 1 (2013): 13-17.

23 "Test of Competence," University of Northampton, accessed May 19, 2018, https:// www.northampton .ac.uk/about-us/services-and-facilities/nmc-test-of-competence/nursingand-midwifery-council-eu-aptitude-test/. 
Council of Europe. "Convention on the Recognition of Qualifications concerning Higher Education in the European Region.” Accessed 3 April 2018. https:// www.coe.int/en/web/conventions/full-list/-/conventions/treaty/165.

Council of Europe. "Imagine for a Second." Accessed April 1, 2017. https://www. coe.int/en/web/education/documentary-on-project-european-qualificationspassport-for-refugees.

Council of Europe. "New recommendation on recognition of qualification held by refugees." Accessed February 27, 2018. https://www.coe.int/en/web/education/-/ new-recommendation-on-recognition-of-qualifications-held-by-refugees.

EAIE. "EQPR: From vision to reality.” Accessed March 30, 2018. https://www.eaie. org/blog/european-qualifications-passport-refugees.html.

ENIC-NARIC. "Recognise qualifications held by refugees - guide for credential evaluators." Accessed March 23, 2018. http://www.enic-naric.net/recognisequalifications-held-by-refugees.aspx.

European Commission. "Eurostat." Accessed March 2, 2018. http://ec.europa.eu/ eurostat/search?p_auth=80e9bK8q\&p_p_id=estatsearchportlet_WAR_ estatsearchportlet\&p_p_lifecycle=1\&p_p_state=maximized \&p_p_ mode=view\&_estatsearchportlet_WAR_estatsearchportlet_action=search\&text $=$ asylum+seekers.

Fohrbeck, Dorothea. "Recognition of foreign professional qualifications - the Federal Government's new Recognition Act." Berufsbildung in Wissenschaft und Praxis (Vocational Training in Research and Practice), Special Edition (2013): 9-13.

González, Julia, and Robert Wagenaar, eds. Tuning Educational Structures in Europe. Bilbao: University of Deusto, 2003.

Gonzalez, Luz, ed. Higher Education in Latin America: Reflections and Perspectives on Nursing. Bilbao: University of Deusto, 2014.

International Council of Nurses. "An implementation model for the ICN framework of competencies for the generalist nurse." Geneva: ICN - International Council of Nurses, 2003.

Marshall, Martin N. "The key informant technique." Family Practice 13, no. 1 (1996): 92-97.

NOKUT. "Nokut's qualification passport for refugees." Accessed April 4, 2018. https://www .nokut.no/en/nyheter-2016/NOKUTs-Qualifications-Passport-forRefugees/.

Saad Eswi, Abeer, ed. Reference Points for the Design and Delivery of Degree Programmes in Nursing. Bilbao: University of Deusto, 2016.

Stievano, Alessandro, R.Caruso, F. Pittella, A.F. Shaffer,G. Rocco, and J. Fairman. "Shaping nursing profession regulation through history - a systematic review." International Nursing Review 66, no.1 (2018): 17-29.

Swanborn, Peter. Case study research: What, why and how? London: Sage, 2010.

Tuning Academy. "Tuning Projects." Accessed February 22, 2018. http:// tuningacademy.org/. 
UNHCR. "UN Refugee Convention.” Accessed March 6, 2018. http://www.unhcr. org/pages/49da0e466.html.

University of Northampton. "Test of Competence.” Accessed May 19, 2018. https:// www.northampton .ac.uk/about-us/services-and-facilities/nmc-test-ofcompetence/nursing-and-midwifery-council-eu-aptitude-test/.

\section{About the authors}

MARIA CASSAR (maria.cassar@um.edu.mt), RN, PhD, is Head of the Department of Nursing and Co-ordinator of the Masters programme in Nursing at the University of Malta. She is a qualified nurse, and currently holds a senior lecturer post at the University of Malta. Her academic commitments include lecturing across various undergraduate and post-graduate programmes at the University of Malta and thesis supervision of both under graduate and postgraduate students in Malta and Universities in the UK. She pursued nurse training in Malta, and later completed masters and doctoral programmes in nursing in the UK, where she resided for a decade. She has worked in many countries spanning the US, Africa (Angola), India and a couple of European countries. Her main professional interests are curriculum design and development, internationalisation, evaluation and quality assurance of higher education programmes. She has participated in two Tuning projects; Tuning-MEDA and CALOHEE projects. Dr Cassar's research interests lie within the field of education, specifically in education for the health and social sector workforce, including both professional and nonprofessional staff, and in aspects of education pertaining to workforce development, retention and mobility. 


\title{
Using the Internationally Recognized Frameworks of Nursing Competences to address the challenges of nurse refugees without documentation
}

\author{
Maria Cassar
}

doi: http://dx.doi.org/10.18543/tjhe-8(1)-2020pp53-73

\section{Copyright}

Copyright for this article is retained by the Publisher. It is an Open Access material that is free for full online access, download, storage, distribution, and or reuse in any medium only for noncommercial purposes and in compliance with any applicable copyright legislation, without prior permission from the Publisher or the author(s). In any case, proper acknowledgement of the original publication source must be made and any changes to the original work must be indicated clearly and in a manner that does not suggest the author's and or Publisher's endorsement whatsoever. Any other use of its content in any medium or format, now known or developed in the future, requires prior written permission of the copyright holder. 